\title{
Poverty Reduction and Female Loan Recipients: Comparing Non-Profit vs. For-Profit Microcredit Programs' Supplemental Services
}

\author{
Jill W. Sinha and Rebecca L. Thomas
}

The majority of loans through microfinance programs are received by women and both Non-profit (NP) and for-profit (FP) organizations also offer other services. This study explored an assumption that NP providers would offer supplemental programming such as child care, health care, or education, and participation in local or regional advocacy efforts. Conversely, the expectation was that FP providers would charge higher rates and fees, offer financial services, business planning, and savings, rather than child or health care, or education. Seventeen programs offering microfinance in large city in India were surveyed, including (8) non-government organizations (NP) and (9) non-banking financial institutions (FP). The data confirmed that FP providers reported higher interest rates, larger loan amounts, and less children's education or childcare. Both types of providers about equally reported other services. We discuss implications for the benefits of both NP and FP models and gendered poverty reduction.

Keywords: microfinance, gendered poverty reduction, mixed markets, For-Profit Non-Profit relationship

\section{Introduction}

Microfinance as a gendered poverty-reduction approach

Microfinance offered through non-profit (NP)/NGOs and for-profit (FP) lenders provide access to loans for families below the poverty rate who are likely to

Jill W. Sinha, PhD., Partner, Arsin Partners LLC, consults with non-profits on strategic planning, development, and evaluation, 2112 Fairwold Lane, Fort Washington, PA 19034. Rebecca L. Thomas, is the Associate Professor of Social Work, University of Connecticut School of Social Work, Director, Center for International Social Work Studies, Chair of CSWE Commission on Global Social Work Education, University of Connecticut, 38 Prospect St. Hartford, CT 06103. Jill W Sinha and Rebecca L. Thomas can be contacted at jwsinha@arsinpartners.com and rlthomas@uconn.edu. 
be ineligible or restricted in access to formal banking institutions. Poverty is largely feminized: demographics consistently indicate that women and children are the most vulnerable to persistent poverty and are the worlds' poorest citizens. The reasons for the gendered face of poverty work together: women typically are engaged in the lowest-paid types of work or informal economy; women earn $24 \%$ less than men even in equitable jobs; fewer women than men are in the paid labor force; and women contribute significantly more time and "work" to activities such as housework and childcare (OXFAM; United Nations Development Program (UNDP), 2015).

In Bangladesh and in developing countries where microfinance has proliferated, the microfinance approach has targeted women as loan recipients. The 2015 Microfinance Summit Campaign Report estimated that out of some 211 million microloan clients, over 80\% were women (State of the Campaign, 2015). Given that women disproportionately provide both unpaid care for children and daily housework needs, our study asked whether the profit motive of the provider, broadly categorized as for-profit (FP) or non-profit (NP) would be related to a) the type of supplemental services offered by the provider, b) the interest rate or fees charged, or c) the provider's engagement in other advocacy efforts for the poor.

The literature review proceeds by appraising the gendered nature of poverty, including the disproportionate nature of women's unpaid contribution to household care and childcare. We then provide an overview of microfinance initiatives and our rationale for why the profit-motive of the provider (FP or NP) may be related to a difference in supplemental services offered, interest rates and fees, and provider's engagement in advocacy efforts.

\section{Women and Income-Generation}

The focus on women and their paid and unpaid labor is strategic for several reasons. Statistics from the United Nations "The Worlds Women 2010" report indicate that globally, women contribute about $52 \%$ of the labor market and that this level has been steady from 1990 to 2010. During this time period, men's participation in the labor market declined from 81 to $77 \%$. Despite the increase among women's participation in the labor market, in all regions of the world, the surveys of developing and developed countries indicate that women spend on average, two to ten times as many minutes per day than men on unpaid domestic work, who spend on average one half hour to two hours per day (Ferrant, Pesando \& Nowacka, 2014).

Put another way, in addition to their paid labor, women from all countries spend, on average, two and a half to six hours per day in activities such as child care, care for other dependents, cooking and preparing food, washing dishes, laundry, household errands, fetching water, collecting firewood, and managing household needs. The norms within many cultures dictate that women, in the words of a Kiva.org fellow, are "obliged to stay at home to look after their children. 
The children are often numerous, ranging greatly in age, meaning that women are generally homebound for most of their adult life" (Hamilton, 2011).

This imbalance between men's and women's contribution to household and children's care activities is unsurprising. Yet, as a factor in women's income-generating ability, it requires specific attention. The difference in hours devoted to unpaid domestic care is larger in developing countries, where women, compared to men, contribute 6 hours per day to men's less than 2 hours per day on comparable activities. The OECD "Employment: Time Spent in Paid and Unpaid Work, by Sex" table (2020) indicates that for all OECD countries, on average, men contribute 2 and a quarter hours per day to unpaid labor and women contribute 4 and one-third hours per day to unpaid labor. Girls, like women, in less developed regions, contribute more unpaid work in their own household than boys. Further, school attendance declines more steeply for girls than for boys, as time spent on household chores increases (United Nations, 2010).

In India, where this study occurred, men's contribution to unpaid labor ranged from 31 to 52 minutes per day, compared to women' 5 to 5.5 hours per day (UNDP, 2015). Conversely, men in India contribute more hours than women to paid labor, where men's average contribution to paid work is 6 to 6.5 hours per day compared to women's 3 hours per day of paid labor. On average then, men contribute a total of 7 and a half hours per day to paid and unpaid labor, to women's 9 hours per day to paid and unpaid labor (Organisation for Economic Co-Operation and Development, OECD.Stats, 2020; UNDP, 2015).

The larger proportion of unpaid labor which women contribute daily constrains women's time and opportunity for paid labor and income-producing activities. Time constraints also impact women's access to and opportunity for other activities which might increase their employability, including education, training, or other social networking or political activities (Cassirer \& Addati, 2007; Razavi \& Staab, 2008). It is this gender-based "vulnerability" in terms of limited access and opportunity for income-producing labor, that make it strategic to target women's access to capital for small business and other income-generating activity through microfinance. A second reason that many microfinance programs have targeted women as loan recipients is evidence that women recipients' income maximizes benefits for family and child welfare. When women's income-earning potential is increased, it has correlated with a reduction in number of children women bear (Mammen \& Paxson, 2000); and, in a recent study from India, an increase in mother's work days; further, increased earning potential was significantly and positively correlated with school attendance and grade level attainment for children, specifically among girls (Afridi, Mukhopadhyay, \& Sahoo, 2013). In addition, some studies show that women devote a greater proportion of the earnings to benefit the family: The study published by the Population Reference Bureau in April 2010 indicated that women spent 90\% of earned income on family needs as opposed to men who spent $30-40 \%$ on family needs (Population Reference Bureau, 2010). Additional earnings to families are invested in additional food or meat for the family, costs of schooling, such as books, and healthcare or medicine 
(Watson \& Dunford, 2006). In some studies, when additional income was earned by male loan recipients, earnings were more likely to also be spent on habits which do not directly benefit other family members.

In sum, the benefits noted above line up with five of the 17 United Nations Sustainable Development Goals, namely: poverty, good health and well-being, quality education, gender equality--especially as gender relates to the stated goals, and decent work and economic growth. Further, this study allow us to discuss the UN SDG question "How do we adjust institutions, decision-making processes, and the mechanisms of management of our global commons to more fairly reflect the new economic and geopolitical order?" (United Nations, 2012).

\section{Microfinance: Brief history and pro's and con's}

The provision of microfinance is a method of poverty-reduction which included women as loan recipients since its inception Bangladesh in the 1980s. Microfinance blossomed in the late 1990s and continues to be a popular anti-poverty initiative, due to its ability to provide: informal credit in the absence of formal credit and its ready alternative in the face of slowness of government, via state and local economic policies, to institute other options for economic uplift among the poorest (Mansurali \& Swamynathan, 2013; Tsai, 2004). In 2008, the United Nations Population Fund and the Microfinance Summit Campaign reported that 3,300 institutions were offering microfinance services to over 133 million clients (2008; 2006). Globally since 2002, the microfinance sector reported the highest rate of growth for the ensuing decade (Mansurali \& Swamynathan, 2013). In addition to providing loans, microfinance programs have been recognized as a conduit for financial assistance and capacity building (Handy, Kassam, Feeney \& Ranade, 2006).

On the positive side, microfinance options can, over time, substantially improve a communities' overall economic outlook: A 14-year longitudinal study by the World Bank on three microfinance institutions in Bangladesh found that $40 \%$ of the entire reduction of poverty in rural Bangladesh was directly attributed to microfinance and supplemental services (Khandker, Khalily \& Samad, 2016). In 2019, the Microfinance Barometer reported nearly 140 million borrowers received loans in 2018; four-fifths of borrowers were female; more than twothirds lived in rural areas with little access to formal banking or credit; and that South Asia is the largest market with just under 85 million borrowers (Stephens \& Khemar, 2019).

At the level of the individual loan recipient, benefits of microfinance may or may not be connected to a community's overall economic improvement but result in tangible and intangible changes. Kiva Fellow Nick Hamilton worked with hundreds of female loan recipients in Colombia, Haiti, and the Dominican Republic and described these benefits: Access to cash that would otherwise not be available; reasonable interest rates rather than exploitive rates from local loan sharks; access to choice--to gain new work or change to work that is different than their 
current situation; access to funds for when catastrophic things happen (devastation from storms or wide-spread violence which affects a whole village); and as intended, access to other services which would support the development one or several microbusinesses or other income-generation, such as childcare, healthcare, insurances, business planning, or training (Hamilton, 2011).

On the negative side, a most concise summary of what is disadvantageous about microfinance as a poverty-reduction strategy was offered by Karnani (2009). Karnani, Associate Professor of Strategy, University of Michigan Ross School of Business, critiqued the inefficiency of microfinance because reliance on private, market-based poverty-alleviation solutions distracts from actions which must be enforced by government to address widespread challenges faced by the ultra-poor: the exploitation of the poor by the market through practices such as single-serving and thus inexpensive items which are luxuries including alcohol or skin-whitening creams; the risks of accidents and poor health without health or unemployment insurance; the lack of adequate wage jobs or government-backed job creation; and the relative inaccessibility or lack of public or private self-help programming to combat alcoholism, train individuals in personal finance and household budgeting, provision of affordable, accessible savings programs, and adult education (2009). Thus, Karnani concluded, private micro-finance options rarely result in sustainable, progressive increases in for microbusinesses and very poor working families. Karnani countered that a better way to eradicate poverty would include job-creation in labor-intensive industries, investing in infrastructure and jobs, and government regulation through legal and economic mechanisms to ensure safety and health, increase education, and maintain infrastructure.

Additionally, Bateman (2010) observed that investing government and private funding into MF schemes diverts resources from other economic policy responses which could impact a wider range of persons living in poverty, including support for pro-poor political parties, collective social movements, trade associations, and single-issue advocacy groups. Although in India the Human Development Index has trended up with positive outcomes, as of 2015, just a quarter of its women were engaged in the formal labor market, while none of its "working poor," which comprised $55 \%$ of total employed persons, had unemployment benefits and just one quarter (24\%) were reported as having an old-age pension account (UNDP, 2015). This and similar critiques - that microfinance does not impact broader social and economic policy causes of poverty, and that policies are in sensitive to rural poor and the gendered nature of poverty, was raised early on in the microfinance literature by Goertz and Sen Gupta (1996), Mayoux (2001), and Pande (2007).

Finally, there are also critiques at the meso-level of the MC programming. Often, loan recipients require multiple or consecutive loans rather than graduating to a being able to earn enough income to generate wealth and savings; that even under the best of conditions, building sustainable microenterprise that could grow to employ more than one or a few persons is very difficult and so cannot offer large-scare income generation in a locale; that only exceptional loan 
recipients tend to scale up to an independently, income-generating microbusiness; that microloan programs are reaching the very poor but not the ultra-poor; and that microfinance cannot address the precariousness of the very poor and working poor affected by illness, emergencies, political violence, or weather that devastates a local economy, or one-time expensive family responsibilities such as weddings and funerals (Banerjee \& Duflo, 2007; Karnani, 2009). These factors impact families' ability to predict expenses, save, or sometimes, to repay a loan which means getting and repaying a loan and getting another, is a common scenario.

Microfinance for Women Loan Recipients: Pros and cons of For-profit and Non-profit Programs

Given this overview of microfinance, we turn here to consider For-Profit (FP) and Non-Profit (NP) providers of microfinance and how the stance toward profit-maximizing or mission-maximizing is reflected by types of supplemental services, and fees and interest rates which accompany loan services for women loan recipients, given that women provide an unequal proportion of unpaid domestic labor and care-giving in addition to the income-generation they might seek to carry out with a microloan.

\section{For-Profit Pros and Cons}

Although microfinance developed as a means to reduce poverty, the provision of microloans can be highly profitable. After 2000, a handful of entrepreneurial investors pushed microfinance from the largely philanthropic approach into a more commercialized FP approach, including SKS which was backed by investors based in Silicon Valley (Kazmin, 2018). Such rapid growth inflows of capital pushed the development faster than the on-the-ground execution could be monitored.

In India, the expansion of FP microfinance programs over the past decade caused investors, government officials and scholars to question both the ethics and the efficacy of FP microfinance programs (Khandker, 2005; Kono \& Takahashi, 2010). High-profile cases with FP providers who serviced high numbers of loan recipients were accused of exploiting clients with high interest rates and fees in order to sustain profitability by lending to every larger numbers of very low-income clients without providing products and services that were designed for and relevant to very low income clients, as discussed at the Seminar on Risk in Indian Microfinance, in Pune India (Sinha \& Banerjee, 2012).

From 2005-2010 as FP providers of microloans proliferated the number of loans, and critics raised alarms that new and bigger loans were being made to already indebted families who were unable to pay back the larger sums, and along with public humiliation by fellow borrowers, contributed to borrower suicides in summer 2010 (Kazmin, 2018). Indeed, the outstanding loans borrowed by MFI clients was reported to have increased from 10 million in 2007 to over 26 
million in 2010, while the average amount borrowed nearly quintupled (Varun \& Raghavan, 2011).

One response was that microfinance lenders were banned from collecting repayment for a time. Several large companies went out of business, and elsewhere banks decreased credit to the FP microfinancing sector. In 2015 the Reserve Bank of India issued licenses for small finance banks to restructure access to credit, requiring these banks to maintain at least half of their loan portfolio with small loans, and mandating additional services in addition to loans (Kazmin, 2018). One large FP lender, Ujjivan, now provides multiple financial services including deposits, remittances, insurance, and investments in addition to loans and very small loans, and offers credit for many purposes, not only microenterprise, and conducts due diligence with individual borrowers to ensure their capacity to make repayments (2018).

Positive attributes of FP provision of microfinance are its emphasis on additional financial services, business planning, and savings support. FP approaches have reached many more individuals with access to credit: in South Asia the three largest markets in terms of number of borrowers, India, Bangladesh and Vietnam, report an estimated 85.6 million persons have received loans (Stephens \& Khemar, 2019).

\section{Non-Profit Pros and Cons}

The "nonprofit approach" is based on the assumption that NPs adhere to a mission beyond that of financial profitability. The US literature on NP social service providers suggests that NPs are likely to be older (in the community longer than 10 years) and more likely to provide an array of other services based on their mission to a particular clientele (Campbell, 2011; Kennedy \& Bielefeld, 2006; Sinha, 2013). That array of services which is peculiar to specific clients suggests that non-profit MF programs will provide other services along with loans, which are concordant with the mission of development-at both the community and individual levels.

One study interviewed women participants in two NP programs based in India: the Working Women's Forum (WWF) and the Guild of Service-Plan (GOS-Plan). These programs are neighborhood-based, have a family focus, and require training on health and nutrition for participants. The women's testimonies suggested that microfinance, supplemented with other services, reduced some of the vulnerabilities associated with poverty (Shetty, 2010). For example, the WWF offers access to health care through workers in the communities where borrowers live, family planning, including education about infanticide, and peer group counseling on issues such as nutrition, contraception, menopause, and maternal health. Other training may be offered, such as leadership skills and job skills, for members who are low-skilled. Job skills training included tailoring, candle-making, and making detergents. Other benefits of these programs ranged from membership in the National Union of Working Women to micro-insurance for life, disability, 
accident and disaster (Women Women's Forum. n.d.). The WWF also organized rallies and events to raise awareness and lobby publicly on women's issues. The WWF is an exemplar of a NP approach of how an array of services are offered that contribute to individual development and community level development in addition to microfinance.

$\mathrm{NP}$ approaches to MF are not without valid criticisms. One limit is that the legal and financial structure of nonprofits typically does not enable them to keep a large amount of capital on hand, which makes them dependent on other funds to sustain the loan pool funding and cash flow. Weinberg (2007) analyzed that while it can be cheaper for the NP to operate the microloan program per borrower, in terms of operating cost, the cost per unit loaned overall is higher: In other words, it can be more expensive for a NP to obtain the actual monies to be loaned. NPs thus may be more constrained in total number of loan recipients at a given time.

We proceed here with the understanding that MF can be an effective tool, and at times, the only credit available to some families for raising their income-generating potential. We were interested in how the supplemental array of services offered via NP or FP providers might support female loan recipients. The questions we asked fell into the following categories. First, what is the array of services offered to loan recipients? Second, were there differences in fees, including interest rate, other fees collected, and loan amounts between NP and FP providers? Third, was there a difference in reported staff engagement in broader advocacy or awareness raising activities around poverty, women's issues, and economic development? We use the data gathered to discuss NP and profit-making approaches to microfinance and whether either of the approaches might better support individual empowerment of female loan recipients in particular.

\section{Assumptions of Study}

The assumption was that NPs which offer microfinance are assumed to have community and individual development as a value in their program goals and encompass a "whole-person" approach. As such, even before offering microloans, NPs may have had "social" programming such as education, child care, skills training (including literacy programs) health care or advocacy already in place that they continue to provide and make available to microloan participants (Milgram, 2005; Thomas \& Sinha, 2009). What is the array of services or supports which are required in order to relieve or support domestic tasks performed by female caregivers, in particular so that they may be enabled to participate more actively in income-generating activity? Child care, health care, and children's education (such as literacy) are examples.

Three sets of assumptions were developed in order to compare observable differences in NPs' "development-orientation” and FPs' financial maximization orientation. The assumptions to be tested include 1) Types of supplemental services or programs offered; 2) Interest rates, service fee amounts and average loan 
amount size; and 3) Participation in local or regional advocacy action/events. The assumptions are rationalized as follows.

First, NP providers' development orientation was expected to result in supplemental services or programs with options for child care, health care, and children's education. Conversely, FP providers' financial maximization approach was expected to result in supplemental services or programs with options for savings programs and business development training.

Second, NP providers' development orientation was expected to result in lower interest rates, lower service fee amounts, and smaller average loan amount size, along with fewer microloan recipients. Conversely, FP providers' financial maximization approach was expected to result in higher interest rates, higher service fee amounts, and larger average loan amount size. Further, FP providers were expected to report larger numbers of loan recipients than NP providers.

Third, FP providers' development orientation approach compared to FP providers' financial maximization was expected to result in variation in staff and microloan recipients' participation in community-level, regional or other collective advocacy actions which would alleviate social symptoms and causes related to poverty. Specifically, it was expected that NP providers would report more frequent staff or loan recipients' participation in events, training, or other programming designed to draw attention to whole family and community needs and policies which are relevant to poor. Such actions or events might include efforts to increase access to clean water, sewage needs, trash removal, health clinics or health services, women's health and nutrition, and education for children. Conversely, it was expected that FP providers would report less frequent engagement in advocacy efforts.

We operationalized the three assumptions as follows.

\section{Assumption 1: Types of Supplemental Services or Programs offered.}

NP providers would more frequently report offering supplemental social services such as child care, health care, nutrition, children's education, and adult skills training or general education.

FPs would more frequently report offering supplemental business and financial services such as insurance, microfinance training, savings programs or business development or marketing guidance.

Assumption 2: Interest rates, service fees amounts; number of loan recipients, and average loan amount size.

NP providers would report lower interest rates, lower service fee amounts, fewer loan recipients, and smaller average loan sizes.

FP providers would report higher interest rates, higher service fees, larger numbers of loan recipients, and larger average loan amounts. 
Assumption 3: Participation in local or regional advocacy action/events.

NP providers' staff and loan recipients would report more frequent participation in advocacy action or events which are relevant to the needs of the poor women.

FP providers' staff and loan recipients would report less frequent participation in advocacy action or events which are relevant to the needs of the poor women.

\section{Methods}

Our web-based search yielded 17 organizations in one large city in India, which were providing MF and had reported publicly available information. Based on the self-reported descriptions, the organizations were categorized as FP (NonFinancial Banking Institutions or NFBIs) and NP organizations. The data, along with annual reports of the organizations indicated how many individuals received loans, gender of loan recipients, interest rates, service fees, average loan amount size, range of loan amounts, and types of additional services available to loan recipients. We used annual reports to gather information on organizations' participation in advocacy and community-related events along with information on the organizations' date of origin and mission statement. A survey was developed to confirm publicly reported data. A link to the web-based survey was e-mailed to an organizational contact — preferably a director or program manager if titles were identified. Where discrepancies were noted, we conducted follow up phone calls to confirm published reports and reported survey data.

The following information on the MF organizations were compiled: loan amounts, effective and nominal interest rate, and reported repayment rate. Supplemental services were categorized as economic programs, such as microfinance training, group formation, financial services, insurance, and business development, or social, such as individual developmental programs, childcare, education, healthcare, and political/social empowerment and advocacy.

\section{Description of sample}

The $17 \mathrm{MF}$ programs were categorized as $\mathrm{NP}(\mathrm{N}=8)$ and $\mathrm{FP}(\mathrm{N}=9)$, based on their designation as a non-governmental organization (NGO) or non-financial banking institution (NFBI). NP providers in the sample were "older," with an average of 22 years in existence. NP providers' years in existence ranged from five years to 35 years and nearly all (7) existed 15 years or more. The remaining one NP existed fewer than 10 years. FP providers in our sample were "younger," in existence fewer years, with an average of 11.8 years in existence, ranging from five years to 25 years. Two FPs had been in existence more than 15 years, while two-thirds (6) of the FPs had been in existence less than 10 years.

The typical participants among both NPs and FPs were primarily poor women. Among FPs the microloan recipients were described as more varied, including two (2) providers which focused on girls (adolescents) and women who experience 
extreme poverty, and people with disabilities. One NP provider identified microloan recipients as agriculture workers, indigenous peoples, refugees, or people who were resettling.

\section{Findings}

Assumption 1: Types of Supplemental Services or Programs offered

\section{Social services for children}

Almost all the NPs, or six (6) reported school/education programs for children compared to about half or three (3) FPs. Regarding childcare specifically, three (3) $\mathrm{NP}$ and no (0) FP providers reported providing childcare or education for children.

\section{Social services for adults}

Regarding education for adults, three (3) NP providers and three (3) FP providers reported offering adult "school or education" for adults.

Regarding health care, into which three categories were combined, namely: "healthcare" "health education," and "nutrition;" five (5) NP providers and four (4) FP providers responded that they offered one or more of these three categories (health education, care, or nutrition).

\section{Microfinance, Financial and Business Services}

Regarding training or services related to microfinance, financial and business development, for adults, both NP and FP providers reported services. Regarding microfinance training and group formation, 6 FP providers and four (4) NP providers offered these services along with the loan. Six (6) FP and three (3) NP providers offered additional financial services and insurance. Among FP providers, there were ten (10) responses specific to microfinance training and insurance, while only two (2) NP providers specifically reported these two areas of service provision. NP and FP providers about equally-- four (4) NP and three (3) FP providers reported offering "business development and/or marketing."

Assumption 2: Interest rates, service fees amounts; number of loan recipients, and average loan amount size

\section{Interest rates, service fees amounts; and average loan amount size}

Regarding interest rates, NP providers' average interest rate ranged from a low of $12.5 \%$ to a high of $24.83 \%$, with an average interest rate of $15.4 \%$. The interest rate for FP providers ranged from a low of $19.75 \%$ to a high of $27.29 \%$ with an average interest rate of $25.28 \%$. Overall, NPs had a lower average interest of $15.4 \%$ compared to the average interest rate of $\mathrm{FP}$ at $25.28 \%$. 
Service fees

There was little difference in service fee amounts reported. For both FP and NP providers' fees ranged from $1 \%$ to $4 \%$. Two (2) NP providers indicated that a proportion of the service fee was used to support individual or collective savings, or a mentoring service.

\section{Number of loan recipients}

The number of loan recipients reported varied widely between FP and NP providers. The number of loan recipients for NP providers ranged from a low of 50 to a high of 332,000 recipients, with an average of about 85,000 loan recipients. The number of loan recipients for FP providers ranged from a low of 166,000 to a high of 7.3 million loan recipients, with an average of 2.3 million loan recipients.

\section{Average loan amounts}

The range of money (loan amount) distributed per loan differed. NP providers' average loan size ranged from RS. 2,680 - 22,500. FP providers' average loan size ranged from RS. 4375 - 131,000. Overall, NP providers reported a smaller average loan size (14,000Rs) compared to FP providers larger average loan size (70,000Rs).

Assumption 3: Participation in local or regional advocacy action/events

Participation in empowerment and advocacy

Participation was categorized into two categories termed "Political/Social Empowerment" and "Political/Social Advocacy." Additionally, in open-ended statements, some providers described community development actions around improved sanitation and advocacy or action to ensure drinking water. Six (6) NP providers reported engaging in advocacy, empowerment or community development and four (4) FP providers reported engaging in these areas. Of these, two (2) NP providers and one (1) FP provider reported programs to assist with Sanitation and/or Clean Water.

\section{Discussion}

This study examined three assumptions in order to compare NP and FP microloan providers and their development orientation versus a financial maximization approach. The three assumptions compared the types of supplemental services or programs offered; the interest rates, service fees amounts, number of loan recipients, and average loan amount size; and reported frequency of participation in local or regional advocacy actions or events. 


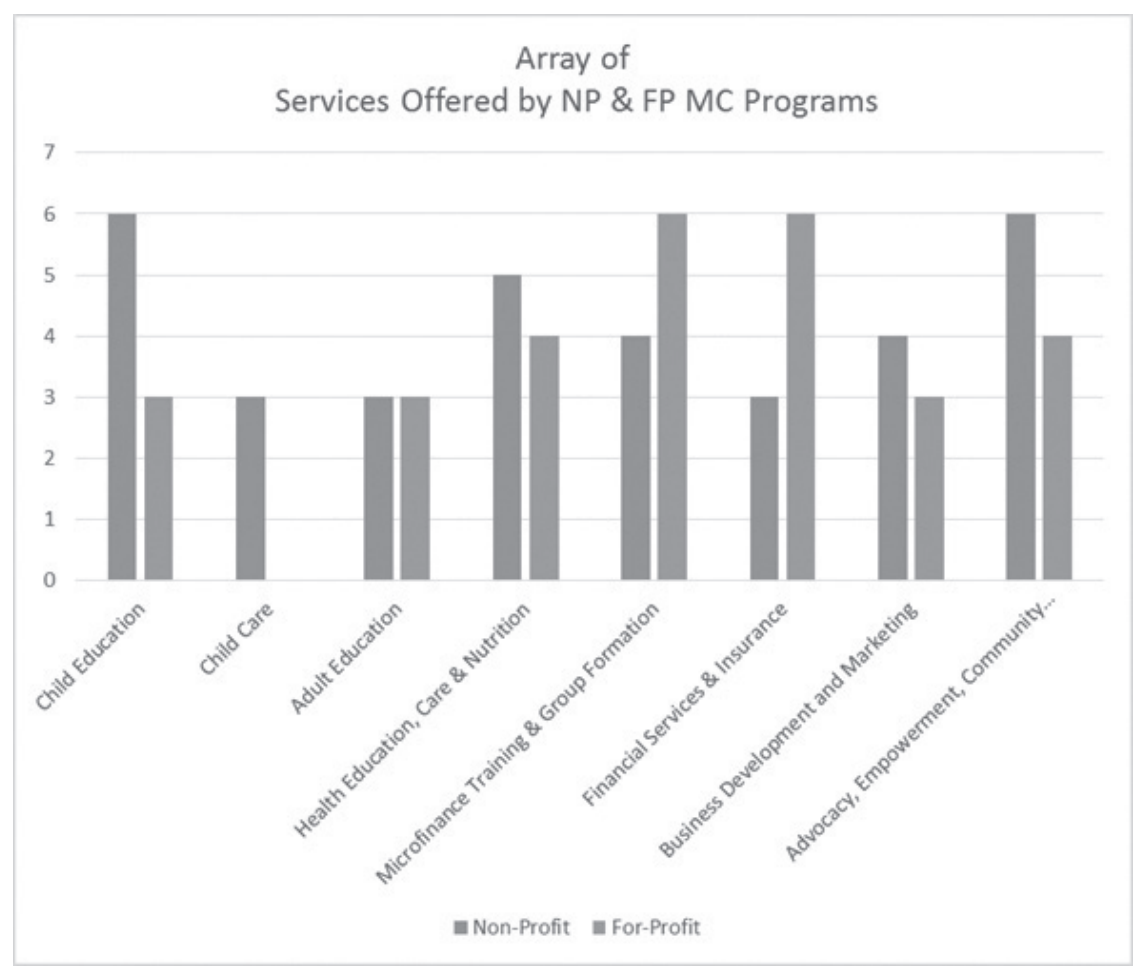

Figure 1 Array of Services Offered by NP \& FP Programs

The sample confirmed that NP providers were "older" on average, at 22 years in existence, compared to FP microfinance providers, who reported an average of 11.8 years in existence. We surmise that the length of time spent in a community correlates with NP providers' familiarity with community members, and further suggest that this knowledge contributes to a deeper understanding of the kinds of challenges that microloan recipients encounter in their efforts to start or expand a micro business or generate income.

While the overall age of the organization was obtained, the date that the microfinance program started was not known. Thus, an organization may have been in existence for a long period of time (more than 15 years) while the microfinance program was more recently implemented. Generally though, we assert that the age of the of the organization contributed to the likelihood that NP providers were already offering an array of supplemental services and that these services were more likely to include individual human development, children's and community development.

FP providers were younger and were more likely to have been created specifically to promote access to credit, financing and microfinance. FP providers also 
offered a surprising array of supplemental services including school or education for children ( 3 FPs), and for adults, offered "health care, health education or nutrition" (4 FPs).

Generally speaking, the data supported the direction of the assumption about the types of supplemental services or programs which were offered by NP and FP providers. Specific to children, nearly twice as many or six NP providers compared to three FP providers reported offering children's education, and three (3) NP providers offered childcare while no FP provider reported offering childcare. This is not surprising: Childcare is an "expensive" and intensive service to provide, in terms of staffing, training and risk, and cost.

Both FP and NP providers reported offering microfinance training and group formation, financial services like a savings program, insurance, and support for business development or marketing. As expected, FP providers were more likely to offer microfinance training (6), and financial services and insurance (6) while fewer NP providers (4), and (3) respectively, reported offering these two areas of supplemental services. One more, or four NP providers reported offering business development and marketing support as compared to three FP providers.

This study was limited in that it could not assess what proportion of loan recipients might need or use childcare or education of children if that were available. In one organization in the sample, nearly two-thirds of loan recipients also used other services provided by the NP: $20 \%$ of the beneficiaries at one site and $30-35 \%$ at a second site attended adult literacy classes and $60 \%$ of all loan recipients' children attended the community center or school. This finding of how commonly supplemental development services were utilized provides evidence that for women's and families' long-term economic development, the provision and use of additional services which specifically include childcare and education of children, may better enable women to participate in income generation and potentially be more effective at reducing inter-generational poverty, than the use of financial and business development alone.

Several findings were surprising, in that both FP and NP about equally reported providing adult education and health education, care and nutrition services. That about the same proportion of all NP and FP providers reported providing education, and health education, care or nutrition, was not expected. In addition, while more NP than FP providers reported engagement in wider advocacy efforts, such as trainings and community events, it was unexpected that three FP would also report doing so. These findings deserve more information to better understand the involvement of FP providers in health education, care and nutrition and advocacy at the community level.

FP and NP providers reported similar repayment rates, ranging from $97 \%$ to $99.7 \%$ and with correspondingly small default rates. This finding is consistent with the wider literature on repayment and default rates for microfinance among the very poor (Dowla \& Barua, 2006). It has not been studied whether these high repayment rates are related to the high proportion of women borrowers or whether this trend would be observed among all microloan recipients. 
As expected, FP providers on average, charged a higher interest rate-about $10 \%$ higher on average, than the NP organizations. However, there was no noticeable difference in the fee rates. One caveat is that two of the NPs used the collected service fee to support individual or collective funding, and "give back" to the community in this way. Similarly as expected, FP providers offered a far higher average loan and upper loan limit at RS. 70,000 (ranging from [RS. 4375-131,000]), possibly suggesting a client base with more developed businesses or average household income that is higher than $\$ 1$ to $\$ 2$ per day. It may also be that when a much larger pool of borrowers are serviced, such as is the case in FP providers in this sample, that the risk of non-repayment is reduced and the larger average loan size offered keeps the pool of borrowers at a maximum. This difference in the average amount of the loan would appear to be consistent in terms of the differing rationale and motive of the FP and NP approach to clients and their legal and financing structure. The FP model seeks to maintain its capital and reduce individual client and stakeholder risk. The NP model seeks to develop individual participants' household capacity and income-generation.

\section{Implications}

A most critical implication for this study is whether the NP or FP orientation appeared to be more supportive of women. All the organizations in this study targeted women as the loan recipients. Women, as noted, while engaging in income-generative activities, are largely responsible for other unpaid labor - in India about 5 hours per day on care of the home, relatives, and children, while men reported spending less than 1 hour is such activities. Further, the type of paid work typically available to poor or working poor women is lower paying, or is in the informal economy. Even when engaging in similar work as a man, women earn $24 \%$ less.

The study assessed whether FP and NP approaches to microcredit were observably different in the array of other services offered to women and considered whether either approach would be more effective at strengthening women's development, that is, her ability to engage in paid work or entrepreneurial activities. One caveat is that among the very poor, it has been found that continuing access to additional loans over several years may be required to support participants through initial business creation and expansion phases until profits or growth are stabilized. With that in mind, how might the findings about varied supports from a FP or NP program matter for women loan recipients?

As with many complex realities, when we looked carefully at 17 organizations located in one large city in India, we found a nuanced picture of service provision among NP and FP providers of microfinance loan services. Even our simple comparison of interest rates, fees, and array of supplemental services in this small sample of providers suggested there may be differing benefits of NP and FP approaches, rather than that a clear preference emerged for one or the other approach and the differing reality for women. For example, for individuals who 
will benefit most from access to credit and savings support and who do not need other services, the FP approach could be most efficient. Other individuals who seek a loan might have more need for skills training, or health care or child care and may be better served by an organization which can offer a range of services along with the loan.

Another implication which deserves discussion is whether the use of public funds to support microfinance programs actually diverts resources from other poverty-reduction strategies which might better serve a larger population of poor and poor women. For example, poverty-reduction investments on pro-poor political parties, social movements, job creation, and trade associations, may be more effective at reducing poverty for a broader portion of society (Bateman, 2010; Karnani, 2007; Takahashi, Higashikata, \& Tsukada, 2010). The UNDP Human Development Report (2015) indicated that of India's employed, 55\% are classified as "working poor" or making \$2 or less per day. The report also states that $0 \%$ of unemployed persons aged 15-64 have unemployment benefits, and just $24 \%$ of the older population receive any pension.

Regarding women in the labor force, the UNDP Report indicated that $27 \%$ of women are engaged in formal labor and this proportion is far below the average for developing countries (at close to 50\% participation of women) and below the average for other countries which are considered "medium" range for the Human Development Index (in which women's participation is 37\% employed). The reality of what types of public spending would most benefit the poor and poor women in particular, is difficult to examine, especially given the highly gendered nature of poverty in both developing economies as well as more developed economies. Among very poor women, it may be that supplemental services, such as education for children, childcare and healthcare, are the very supports which enable women to enter into or expand income-earning activities (Drolet, 2009). This population of poor and working poor will be served through policies that support social inclusion in the job sector, job creation, and the expansion of state, local and significantly, national social security and income stability programs which are designed for broad eligibility. Second, women as entrepreneurs and wage-earners will be better able engage in paid work when their caregiving burdens are shared. Affordable, safe, high quality childcare, subsidies for childcare, protected paid leave, and leave for childbearing are examples of supports which help women to manage paid labor and caregiving responsibilities.

These very supports also promote a new set of cultural and domestic expectations among a younger generation of both girls and boys. Shifting gender-based cultural and social expectations is a daunting and slow-moving process. When boys and girls are equally encouraged and expected to devote time to the support of the home and caregiving, then future generations of women and men will have more choice to engage both in income-producing, educational and training activities and in the important unpaid labor of caregiving and caring for a home. In other words, until the gendered disparity in hours devoted to unpaid caregiving 
and household responsibilities is reduced and becomes more equitable, women will not be able to engage more in paid work. As stated succinctly by Garikipati, Johnson, Guérin and Szafarz (2016), "Gender inequalities are shaped by (and constituted of) many power inequalities that transect social, economic, cultural and political structures" (pg. 4).

Very few women--exceptions really, have all the conditions, or can control all the conditions needed in order to grow a sustainable business that can support themself and dependents such as children. Such conditions include the woman's temperament, aptitude and health, number of children she is responsible for, the presence of supportive family members who can assist with household tasks, reliable provision of childcare, cooking or laundry along with business tasks, training, business acumen, and also luck and stability within a local economic market. Only when these conditions are met in a predictable or stable way is it likely that a women can start and substantially expand into sustainable income-generating activity. Many of the conditions noted above are ones over which a woman may have very little control.

Our study was limited by a small sample, unknown representativeness of the organizations, and limited publicly available information. Yet, our findings suggests that NP providers are more likely than FP providers to offer at least some "expensive" supplemental service--namely education of children or childcare, along with basic adult education or training, and to do so while offering loans with interest rates that are lower by about $10 \%$ on average. If nothing else, this finding suggests that a NP development orientation is more beneficial for the average women loan recipient especially if she also has young children.

There are some exceptionally gifted, and hard-working women who can and do build sustainable income-generative business starting with micro-credit. Reports from one of the programs in this study observed that "success stories" occurred especially with mature women whose children were older and more self-sufficient. That is not the only "success" story of microcredit: Many female loan recipients benefit from a loan and other supplemental services in their journey towards income-generating activities, and likely would not have these opportunities if it were not for the MC programs provided by FP and NP providers. As noted by Kiva fellow Hamilton, intangible and tangible benefits to women who are loan recipients include choice, hope, training, childcare, access to health care, access to collective training, advocacy opportunities, and additional income. Even when additional income may be small, these benefits, and the example they offer to younger generations of girls and boys are worthwhile.

As a final note, we acknowledge the limited capacity of microfinance programs to affect the structural factors which severely restrain very poor women's entry into income-generative activity. A comprehensive approach toward poverty-reduction must occur systematically at macro and meso levels. We applaud the models of such organizations as Kiva, SEWA, Ujjiva, Interactuar, among others which effectively combined loan and savings programs with education and social reform through their sizeable member base. Sewa International organized 
construction workers to voice their demands leading to The Construction Workers Welfare Protection ACT of 1996 (Jhabvala \& Kanbu, 2002). They also pushed the government to pass an act that would allow for privatization of insurance to make health insurance more accessible to poorer women (Jhabvala \& Kanbur, 2002). Further research on outcomes of male vs female loan recipients at FP (NBFI or small-banking institutes) and NP microloan providers would be of great interest. Such research could also control for the factors we identified here such as types of supplemental services provided.

We affirm the efforts of both FP and NP providers to advocate at the organizational and community level to improve the daily life quality of loan recipients. We advocate for nonprofit and FP models which commit to and carry out activities through which loan recipients must work together and think critically about longer term solutions for their respective communities. Mandatory activities might include meetings with local businesses, government officials, and other development agencies in order to increase awareness and promote understanding of what types of public policies and agreements must be altered so that more people may share the benefits of economic growth. It is difficult to estimate the benefit of soft-skill development, such as networking, choice, confidence-building, and participation in assessing community needs for primary informal education, primary health clinics, safe drinking water, or a community latrine. Such "soft" skills are both fundamental and transferable and can support wider awareness, lead to self-advocacy and the type of collective social action which are required in advance social change including access to credit, and to long term equity and quality of life for more individuals in developing economies.

\section{References}

Afridi F., Mukhopadhyay, A., \& Sahoo, R. (2013, March). Female labour-force Participation and Child Education in India: The Effect of the National Rural Employment Guarantee Scheme. No 6593, IZA Discussion Papers, Institute of Labor Economics (IZA)

Banerjee, A. \& Duflo, E. (2007). The Economic Lives of the Poor. Journal of Economic Perspectives, 21, 10.1257/jep.21.1.141.

Bateman, M. (2010). Why doesn't microfinance work? The destructive rise of local neoliberalism. London: Zed Books.

Campbell, D. (2011). Reconsidering the implementation strategy in faith-based policy initiatives. Nonprofit and Voluntary Sector Quarterly, 40(1), 130-148.

Cassirer, N. \& Addati, L. (2007). Expanding women's employment opportunities: Informal economy workers and the need for childcare, Interregional Symposium on the Informal Economy: Enabling Transition to Formalization, 27-29 November 2007 (Geneva).

Dowla, A. \& Barua, D. (2006). The poor always pay back. Bloomfield, CT: Kumarian Press. 
Drolet, J. (2010) Women and microfinance: Implications for social and economic development. Social Development Issues, 31, 56-68

Ferrant, G., Pesando, L. M., \& Nowacka, K. (December, 2014). Unpaid care work: The missing link in the analysis of gender gaps in labour outcomes. Working paper of the OECD Development Centre.

Garikipati, S. Johnson, S., Guérin, I. \& Szafarz, A. (2016). Microfinance and gender: issues, challenges and the road ahead. The Journal of Development Studies, 53(5), 641-648 doi: 10.1080/00220388.2016.1205736. Retrieved from http://dx.doi.org/10.1080/00220388.2016.1205736

Goetz, A.M. \& Sen Gupta, R. (1996). 'Who takes the credit?' Gender, power, and control over loan use in rural credit programmes in Bangladesh, World Development, 24(1), 45-63.

Hamilton, N. (2011). The pros and cons of Microfinance-A view from thefield. Kiva. org.blog. https://pages.kiva.org/blog/the-pros-and-cons-of-microfinance-aview-from-the-field-part-1

Handy, F., Kassam, M., Feeney, S., Ranade, B. (2006). Grassroots NGOs by women for women: The driving force of development in India. Sage.

Jhabvala, R., \& Kanbur, R. (2002). Globalization and economic reform as seen from the ground: SEWA's experience in India. Available at: https://www. wiego.org/publications/globalization-and-economic-reform-seen-ground-se wa $\%$ E2\%80\%99s-experience-india

Karnani, A. (2009), Romanticising the poor harms the poor. Journal of International Development, 21: 76-86. https://doi.org/10.1002/jid.1491

Kazmin, A. (2018, September). Indian microfinance gives birth to smaller banking model.

Financial Times. Retrieved from https://www.ft.com/content/0b3dd4ce-807711e8-af48-190d103e32a4

Kennedy, S. S. \& Bielefeld, W. (2006). Charitable Choice at work: Evaluating faithbased job programs in the states (Washington, DC: Georgetown University Press.

Khandker, S. (2005). Microfinance and poverty: Evidence using panel data from Bangladesh. World Bank Economic Review, 19(2), 263-285.

Khandker, S. R., Khalily, M. A. \& Hussain A. S. (2016). Beyond Ending Poverty: The Dynamics of Microfinance in Bangladesh. Directions in Development. Washington, DC: World Bank. doi: 10.1596/978-1-4648-0894-4. License: Creative Commons Attribution CC BY 3.0 IGO

Kono, H. \& Takahashi, K. (2010). Microfinance Revolution: Its Effects, Innovations, and Challenges. The Developing Economies, 48 (1), 15-73.

Mammen, K., \& Paxson, C. (2000). Women's Work and Economic Development. Journal of Economic Perspectives, 14 (4): 141-164.

Mayoux, L. (2001). Tackling the down side: Social capital, women's empowerment and microfinance in Cameroon. Development and Change, 32(3), 435-464.

Mansurali, A. \& Swamynathan, R. (2013). A review on MFIS efficiency and its impact scenario. Journal of Contemporary Research in Management, 8(3) 43-54. 
Milgram, L. (2005). From margin to mainstream: Microfinance, women's work and social change in the Philippines. Urban Anthropology and Studies of Cultural Systems and World Economic Development, 34, 341-383

Organisation for Economic Co-Operation and Development. (2020). Employment: Time Spent in Paid and Unpaid Work, by Sex" table. Retrieved from https://stats. oecd.org/index.aspx?queryid=54757

Razavi, Shahra and Silke Staab. 2008. The Social and Political Economy of Care: Contesting Gender and Class Inequalities, UNRISD's contribution to the Expert Group Meeting organized by DAW, 6-9 October, Geneva. Available online: http://www.un.org/womenwatch/daw/egm/equalsharing/EGM-ESOR-2008-BP3\%20UNRISD\%20Paper.pdf

Shetty, S. (2010). Microcredit, poverty, and empowerment: Exploring the connections. Perspectives on Global Development and Technology 9(3-4):356-39.

Sinha, J. W. (2013). Unintended impact of the Faith-Based Initiative: Examining the use of religious identity among faith-based human services organizations. Nonprofit and Voluntary Sector Quarterly, 42, 563-583.

Sinha, S. \& Banerjee, S. S. (2012, May 6). India's Microfinance Industry: An Anatomy of Risk for April 2012.CGAP (Consulting Group to Assist the Poor) https:// www.cgap.org/blog/indias-microfinance-industry-anatomy-risk-april-2012

State of the Campaign, Microfinance Summit Campaign. (2015). Report. Retrieved from http://stateofthecampaign.org/2015/12/09/read-the-full2015-report/

Stephens, B. \& Khemar, M. (2019). Key figures of financial inclusion / World: Global microfinance figures; What are the trends? Microfinance Barometer 2019 / Convergences. Retrieved from http://www.convergences.org/wp-content/uploads/2019/09/Microfinance-Barometer-2019_web-1.pdf

Takahashi, H. Higashikata, T. \& Tsukada, K. (2010). The short-term poverty impact of small-scale collateral-free microfinance in Indonesia: A matching estimator approach. The Developing Economies 48(1), 128-55.

Thomas, R. \& Sinha, J. W. (2009). A critical look at microfinance and NGOs in regard to poverty reduction for women. Social Development Issues, 31, 30-42.

United Nations (2012). Back to our common future: Sustainable development in the $21^{\text {st }}$ century (SD21) project summary for policymakers. New York: United Nations.

United Nations Development Programme. (2015). Human development report 2015: Work for human development: Briefing note for countries on the 2015 Human Development Report. Retrieved from https://www.undp.org/ content/dam/india/docs/GHDR2015/GHDR-2015-Briefing-India-Explanatory-Note.pdf

United Nations Population Fund and the Microfinance Summit Campaign (2008). Financing healthier lives: Empowering women through integration of microfinance and health education. New York: United Nations Population Fund.

Watson, A. A. \& Dunford, C. (2006). From Microfinance to macro change: Integrating health education and microfinance to empower women and reduce 
poverty. Washington, DC: Microfinance Summit Campaign and New York, NY: United Nations Population Fund.

Working Women's Forum (n.d.) Empower. Enlighten. Engage. Retrieved from http:// www.workingwomensforum.org/index.htm

Weinberg, B. (2008). For-profit Versus Nonprofit Microfinance: How Are the Poor Affected? The Eagle Feather, Retrieved at https://eaglefeather.honors.unt. edu/2008/article/170\#.XtbsIVVKjIU

Varun, \& Raghavan, M. (2011). From Gospel to heresy: The crisis in microfinance. The CriticalTwenties. Retrieved at http://www.criticaltwenties.in/ economicsocialpolicy/from-gospel-to-heresy-the-crisis-in-microfinance. 